\title{
Which statin we should use?
}

\begin{abstract}
Despite huge improvements in the science, a cardiovascular disease (CVD) is still the leading cause of morbidity and mortality worldwide. As one of most important and modifiable CVD risk factor in both children and adolescents having type 1 diabetes (T1DM) and type 2 diabetes (T2DM), dyslipidemia has been considered. Statin therapy has been applied as the most common therapy for declining of cardiovascular risk through the reduction of cardiovascular mortality worldwide in recent decades. This article considers the different types of statins and their doses
\end{abstract}

Keywords: cardiovascaulr diseases, Type 1 Diabetes, Type 2 Diabetes, Statins
Volume 13 Issue 5 - 2020

\section{Masoud Amiri}

Department of Epidemiology, Erasmus Medical Center,The Netherlands

Correspondence: Masoud Amiri, Department of Epidemiology, Erasmus Medical Center, The Netherlands, Tel 0031630964709 , Email masoud.amiri@yahoo.com

Received: November 02, 2019 | Published: October 07, 2020

\section{Opinion}

Cardiovascular disease (CVD) is still the leading cause of morbidity and mortality worldwide despite huge improvements in the science. The original concept on which lipids have to be accumulated and which lipids must remove in order to achieve the ideal disease prevention, has been changed into the new concept on the mechanisms of lipid movement between lipoproteins, cells and organelles involved in CVD. ${ }^{1}$

Dyslipidemia can be considered as one of most important and modifiable CVD risk factor in both children and adolescents having type 1 diabetes (T1DM). ${ }^{2}$ It is believed that atherosclerosis process can start in early life associated with dyslipidemia and continues into adulthood even in people without diabetes. ${ }^{3}$ Therefore, adults with T1D need to receive statin for both primary and secondary prevention of CVD. ${ }^{4}$ In addition, the risk of CVD in type 2 diabetes (T2DM) is the same as CVD patients without T2DM with a heart attack. ${ }^{5}$ Like T1DM, statins can also reduce the risk of CVD in T2DM patients. ${ }^{6} \mathrm{~A}$ greater reduction in low density lipoprotein-Cholesterol (LDL-C) can result in larger reduction in events, especially in secondary prevention and T2DM patients. ${ }^{7}$

In recent years, statin therapy has been the most common therapy for declining of cardiovascular risk through the reduction of cardiovascular mortality worldwide. ${ }^{8}$ There are many types of statins including Atorvastatin, Simvastatin, Lovastatin, Rosuvastatin, Fluvastatin, Cerivastatin, Pravastatin and Pitavastatin. There have been some differences in lipid-modifying ability of different statins in diabetic patients. ${ }^{9}$ There are also some studies on the combination therapy with other medications. ${ }^{10}$

The question for physicians and patients could be which type of statin with how much does is better for the treatment. While it has been suggested that Atorvastatin is the most effective statin, ${ }^{11}$ there is also some recommendation to switch into another statins. ${ }^{12}$ Why the patients should use another statins? Another question would be the effect of combination therapy with other medications such as fibrates. ${ }^{13}$ Which combination could have better impact on lowering lipids?

The third question would be the toxicity of statins which may result in statin-associated muscle symptoms ${ }^{8}$ statin-induced new onset T2DM, statin-induced Ischemic and Hemorrhagic Stroke, statininduced Dementia and Alzheimer disease, statin-induced psychiatric effects, statin-induced hepatotoxicity, statin-induced renal toxicity and statin intolerance. ${ }^{14}$ Which statin has less toxicity and with which dose? The fourth question is the dose of statins. While some studies have shown that the high-dose and low-dose statin therapy have similar effects, ${ }^{15}$ why should the patients receive higher doses? These questions are the questions that need to be answered with more concern on the potential side-effects and contraindications of statins. If you are a physician or patient, which statin will you prefer to use?

\section{Conclusion}

As a conclusion, it should be considered that statins have a substantial role in declining the morbidity and mortality from CVD. However, the various types of statins and different doses can confuse many physicians and patients, while atorvastatin has been approved as the statin with the least side-effects as well as equal effects of high-dose vs low-dose prescription. The further research is needed to determine the fact.

\section{Acknowledgments}

None.

\section{Conflicts of interest}

The authors declare there are no conflicts of interest related to the article.

\section{Funding}

None.

\section{References}

1. Sposito AC, Zimetti F, Barreto J, et al. Lipid trafficking in cardiovascular disease. Adv Clin Chem. 2019;92:105-140.

2. Bjornstad P, Wadwa RP. Risks and benefits of statin use in young people with type 1 diabetes. Curr Diab Rep. 2014;14(7):499.

3. Strong JP, Malcom GT, McMahan CA, et al. Prevalence and extent of atherosclerosis in adolescents and young adults: implications for prevention from the Pathobiological Determinants of Atherosclerosis in Youth Study. JAMA.1999;281(8):727-735.

4. Reiner Z. Statins in the primary prevention of cardiovascular disease. Nat Rev Cardiol. 2013;10(8):453-464.

5. Haffner SM, Lehto S, Ronnemaa T, et al. Mortality from coronary heart disease in subjects with type 2 diabetes and in nondiabetic subjects with and without prior myocardial infarction. $N$ Engl $J$ Med. 1998;339(4):229-234. 
6. Colhoun HM, Betteridge DJ, Durrington PN, et al. Primary prevention of cardiovascular disease with atorvastatin in type 2 diabetes in the Collaborative Atorvastatin Diabetes Study (CARDS): multicentre randomised placebo-controlled trial. Lancet. 2004;364(9435):685-696.

7. Opie LH, Commerford PJ, Gersh BJ. Controversies in stable coronary artery disease. Lancet. 2006;367(9504):69-78.

8. Sposito AC, Faria Neto JR, Carvalho LS, et al. Statin-associated muscle symptoms: position paper from the Luso-Latin American Consortium. Curr Med Res Opin. 2017;33(2):239-251.

9. Wolffenbuttel BH, Franken AA, Vincent HH, et al. Cholesterol-lowering effects of rosuvastatin compared with atorvastatin in patients with type 2 diabetes - CORALL study. J Intern Med. 2005;257(6):531-539.

10. Averna M, Missault L, Vaverkova H, et al. Lipid-altering efficacy of switching to ezetimibe/simvastatin $10 / 20 \mathrm{~g}$ versus rosuvastatin $10 \mathrm{mg}$ in high-risk patients with and without metabolic syndrome. Diab Vasc Dis Res. 2011;8(4):262-270.
11. Schaefer EJ, McNamara JR, Tayler T, et al. Comparisons of effects of statins (atorvastatin, fluvastatin, lovastatin, pravastatin, and simvastatin) on fasting and postprandial lipoproteins in patients with coronary heart disease versus control subjects. Am J Cardiol. 2004;93(1):31-39.

12. Moon JC, Bogle RG. Switching statins. BMJ. 2006;332(7554):1344 1345 .

13. Rosenblit PD. Do persons with diabetes benefit from combination statin and fibrate therapy? Curr Cardiol Rep. 2012;14(1):112-124.

14. Ward NC, Watts GF, Eckel RH. Statin Toxicity. Circ Res. 2019;124(2):328-350.

15. Agrawal D, Manchanda SC, Sawhney JPS, et al. To study the effect of high dose Atorvastatin 40mg versus $80 \mathrm{mg}$ in patients with dyslipidemia. Indian Heart J. 2018;70(Suppl 3):S8-S12. 